\title{
Dos visiones del Descubrimiento y la Conquista: Giuseppe Parini (1729-1799) y Cesare Pascarella (1858-1940)
}

\author{
Mariapia LAMBERTI \\ Universidad Nacional Autónoma de México
}

El Descubrimiento y el sucesivo apoderamiento por parte de España de buena parte del territorio del nuevo continente no tuvieron, en su momento, en tierras italianas, una repercusión política, social o filosófica. Italia (sería mejor decir: los Estados de la península italiana) se veía aquejada en aquellos tiempos por una serie de interferencias extranjeras que bien merecieron ser definidas como "la segunda invasión de los bárbaros"; y asistía, entre impotente y despreocupada, a la mayor catástrofe de su historia: la pérdida de la libertad. Sus habitantes, haciendo buen uso del mayor invento que a ellos se les achaca, el individualismo inmisericorde, se distinguieron inmediatamente como traficantes de esclavos y de mercaderías de todo tipo, absorbiendo las nuevas tierras en su horizonte geográfico-humano (no hay que olvidar las lecciones proféticas de Dante y Petrarca sobre los antipodas) con la mayor naturalidad.

Es sólo cuando la idea de Italia empieza a perfilarse, y que con el tiempo se realiza, que la pérdida de la integridad sufrida por los poderosos imperios mesoamericanos se contempla en toda su dolorosa analogía con las vicisitudes de la patria; la figura del conquistador español empieza a ser denostada por los amargos recuerdos de la dominación padecida en carne propia, y la italianidad de Cristoforo Colombo (que se me perdone la morfofonética patriótica) empieza a ser sopesada como demostración del "genio itálico".

Encuentro en el panorama literario italiano dos ejemplos singulares, interesantes y cada uno en su estilo hermosísimos, de la visión del Descubrimiento y la Conquista. Reveladora resultará también la comparación entre ambos.

Giuseppe Parini (Milán, 1729-1799) representa, en la literatura y en la historia de la civilización italiana, el "eslabón perdido" que conecta a los grandes de la época de oro, Dante, Petrarca, Machiavelli, cuya producción literaria estuvo estrechamente ligada con su compromiso de italianidad, cuando no de política propiamente dicha, con los grandes venideros: Alfieri, Foscolo, Leopardi, Man- 
zoni, Porta, Belli, que caracterizaron el Romanticismo italiano con presupuestos de acendrada pasión patriótica.

Parini, sacerdote de poca vocación, como en sus tiempos era común, pero de alto compromiso moral, como era poco menos que insólito, conoció muy de cerca la sociedad aristocrática lombarda de los decenios prerrevolucionarios, puesto que su oficio sacerdotal lo cumplió casi siempre no en cura de almas, sino como confesor y dómine en casas encumbradas. El preceptor-sirviente, al que durante la misa se le besaba la mano, y al que durante las comidas se le relegaba en una mesa aparte como los lacayos, poeta por vocación temprana, versificador prodigioso por virtuosismo innato y estudio, académico de Arcadia por méritos indiscutidos, concibió un largo y articulado poema, donde se describiera con irónica magnilocuencia, con todas las ampulosidades tardobarrocas de moda, los ocios y las ociosidades que componían el día de un joven de alta clase (un giovin signore como lo llama con un término que ha pasado a la lengua de uso), de una clase desfuncionalizada desde siglos, y decadente y corrupta desde decenios: una especie de épica al revés. La ironía, la sátira, estribaría en los visos de aprobación y consejo que el precettor d'amabil rito, el preceptor-poeta que instruye-canta al alumno hipotético, imprimiría a la descripción de esas veinticuatro horas inútiles y vacuas si no es que dañinas, reprimiendo la indignación y camuflándola de menosprecio de lo bueno y honroso (el trabajo, la hidalguía), y alabanza de lo malo y vergonzoso (la holgazanería y la soberbia de clase).

En la primera parte del poema, llamado Il giorno, y compuesto entre 1763 y 1765 , dedicada al despertar del giovin signore (despertar que por supuesto se verifica a las doce, invalidando el subtítulo de "Il mattino" ["La mañana"] que se da a esta primera parte), existe un pasaje de catorce versos, en los que el preceptor, preguntando al joven señor con cuál bebida exótica planea empezar el día (té, café o chocolate), rememora lo que costó en esfuerzos, atropellos y vidas humanas la llegada de tales bebidas a los labios afeminados del petimetre, reiterando sarcásticamente que todo aquello fue justo y debido en vista de tan alto fin:

Certo fu d'uopo, che dal prisco seggio uscisse un Regno, e con ardite vele fra straniere procelle e novi mostri e teme e rischi ed inumane fami superasse $i$ confin, per lunga etade invïolati ancora: e ben fu dritto se Cortes e Pizzarro umano sangue non istimâr quel ch'oltre l'Oceano scorrea le umane membra, onde tonando 
e fulminando, alfin spietatamente balzaron giù da' loro aviti troni re messicani e generosi incassi; poichè nuove così venner delizie, o gemma degli eroi, al tuo palato. (vv. 144-157)

Menester fue que de su prisca sede saliera un Reino, y con osadas velas entre extrañas borrascas, nuevos monstruos, temores, riesgos y hambres inhumanas los confines pasara, inviolados en luengas eras: $y$ aun fue derecho que Cortés y Pizarro no juzgaran humana sangre la que allende el mar humanos miembros recorria, y tronando y fulgurando, al fin despiadadamente volcaran de heredados tronos reyes mexicas e incas generosos; pues delicias asi legaron nuevas, oh gema de los héroes, a tus labios.

La crítica contemporánea posfascista ha asentado con claridad que la idealidad de Parini no supera los límites del moralismo racionalista del siglo filosófico, y responde a un intento reformista, y no a una inquietud revolucionaria; desmitificando así una imagen que en todo el siglo XIX ( $y$ una parte muy precisa del siglo $\mathrm{Xx}$ ) fue encumbrada a la altura de un prócer fustigador de los mores y precursor de una Italia unida e independiente, regenerada en las costumbres y vencedora de sus enemigos.

Sin embargo, en este excursus poético, breve pero de amplísimo vuelo pindárico, Parini resume con extraordinaria eficacia y contenida piedad todos los aspectos de la gran hazaña: un Reino (nótese: no una persona) abandona su asiento natural y supera confines (o sea límites de contención) que por largas edades 0 eras (término que indica tiempos inconmensurables, que trascenden con mucho la vida humana) no habían sido violados (o sea, forzados contra natura). He aquí el pecado inicial, la ruptura del orden establecido; pero quien lo comete tiene su grandeza, pues con velas osadas (con enálage, el atrevimiento se atribuye al objeto inanimado y no a quien lo anima: casi cubriendo con un velo de pudor la imagen de aquellos navegantes verdugos y víctimas a la vez) sabe desafiar peligros nunca vistos: las hambres inhumanas, las tempestades extrañas, o sea extranjeras, que hacen parte de la naturaleza; pero también los nuevos monstruos que bien pueden ser las circunstancias insólitas, 
a la latina, o los fantasmas de los temores atávicos: elementos resumidos en los términos temores (internos) y riesgos (externos). Aquí termina la primera parte del discurso, que describe el Descubrimiento. Retóricamente, toda la descripción constituye el sujeto de una oración rectora que plantea una premisa de una conclusión que no adivinamos: (seguramente) fue menester, o sea fue necesario, obligado e inevitable. Esta premisa ocupa los primeros cinco versos y medio.

En los siguientes seis y medio, con una estructura sintáctica paralela, la Conquista: tratándose de acción política, el término empleado para la afirmación inicial, irónicamente aprobatoria, es aquí de orden jurídico: fue derecho. En pocas palabras se resumen los términos históricos de su desarrollo: el nombre de los dos protagonistas más célebres (Cortés y Pizarro); sus armas desconocidas a los pueblos agredidos (tronando y fulgurando: cañones y armas de fuego); la amañada justificación inicial del atropello (no juzgando humana sangre la que recorria humanos miembros: donde la repetición del adjetivo subrayada por la calibrada estructura paralela, destaca lo contradictorio del planteamiento alevoso); la actitud moral (despiadadamente, largo y pausado adverbio que campea en el verso); el largo tiempo de la lucha (por fin); la violación (volcaran) del derecho natural hereditario: los tronos americanos son heredados, o sea plenamente legítimos ( $i$ y este concepto depende sintácticamente de una rectora que afirma "derecho"!); y finalmente, en cierre del párrafo y en contraposición paralela con los nombres de los conquistadores, he ahí los conquistados, en plural, para subrayar de algún modo lo extraordinario de la disparidad de fuerzas: reyes mexicanos y generosos incas. Para los mexicanos basta su denominación de "reyes" que reafirma su nobleza legítima; al término "incas", muy exótico, se añade un adjetivo que refuerza la nobleza de alma, "generosos", lo contrario de los despiadados españoles.

Los últimos dos versos concluyen el sarcasmo moralista, rememorando la motivación inicial de los viajes transatlánticos (las famosas especias) y rebajándolo a su más vil significado: el placer del paladar de algunos ricos ociosos.

La colocación, el sentido, la meditada estructura retórica de esta espléndida digresión, que encontramos en una parte que seguramente es la más cuidada y pensada, la más elegantemente cincelada, de todo el poema (que se va cansando hasta el agotamiento conforme procede, y de hecho se quedó inconcluso), no han sido suficientemente subrayadas. ${ }^{\prime}$

\footnotetext{
' Por curiosidad se traduce la nota explicativa que aparece en una edición escolar de $I l$ giorno (a cargo de A. Pellizzari y M. Olivieri. Nápoles, Perrella) sin fecha, pero colocable sin duda en los primeros años del fascismo: "Fernando Cortez [sic], español conquistador de México, combatió despiadadamente y venció con la traición a los indígenas capitanea-
} 
Con esta visión tan intensamente humana, contrasta la que Cesare Pascarella (Roma 1858-1940) nos ofrece en La scoperta de l'America, un largo poema en dialecto romanesco, conformado por cincuenta sonetos, y compuesto en 1893. Dedicado totalmente al Descubrimiento, su redacción se debió con toda probabilidad a la efeméride del cuarto centenario.

Pascarella nació con la formación de la Italia unida e independiente, murió con los estertores del fascismo, y escribió La scoperta de l'America en aquel resquicio del siglo pasado que vio los primeros intentos colonialistas de la nueva Italia. La entonación patriótica y la exaltación del "genio itálico" no puede ni faltar ni extrañar en la obra de un poeta menor, como lo es Pascarella, comprometido con los círculos de la cultura oficial. Gran viajero, Pascarella visitó América, pero conoció del continente sólo Estados Unidos y Argentina: dos naciones altamente europeizadas, donde la presencia indígena se ocultaba con facilidad. Asimismo, del Oriente cercano y lejano conoció únicamente las cunas de las más altas civilizaciones: Egipto, India, Japón.

En los cincuenta sonetos de La scoperta, un plebeyo romano entretiene a sus compañeros de juerga en una taberna contando las maravillas de Colombo (inalterable la morfofonética en el personaje vernáculo) y los exóticos hallazgos que de su esforzada empresa se derivaron. La entonación discursivo-dramática no se pierde nunca, y las voces de los asistentes se dejan oír de vez en cuando, para estimular, contradecir, mofarse del narrador, o hasta para crear escenas costumbristas colaterales. El relato está construido con presupuestos inversos a los del poema de Parini: la entonación bufa y el lenguaje decididamente cómico remiten a un contenido y una intención seriamente encomiástica. El efecto de comicidad, a menudo irresistible, estriba en el contraste entre la realidad "otra" que se quiere describir, y las analogías con el mundo del narrador, que se sacan a colación para dar plasticidad al relato, confeccionado por un ingenuo para otros ingenuos; hay trastocamiento de términos, anacronismos referenciales, compactación de episodios distantes en el tiempo y el espacio, interpretaciones amañadas, y sobre todo el efecto cómico y seguro de hacer hablar romanesco con referentes romanos a Colombos, españoles e indígenas por igual.

La figura de Colombo campea desde el primer soneto que relata el asunto del huevo como prueba esgrimida ante rem por Colombo para convencer a los demás que él sabía che ar monno c'era pure er monno novo, que en el mundo se encontraba también el mundo nuevo.

dos por su emperador Montezuma [sic] (1518); Pizarro, también español, desembarcó en Perú, sometió a los incas que lo habitaban [sic], y mató, contra lo pactado, a su rey". En otra nota se define a todo el proceso como "hórrida e inicua matanza". 
Acto seguido (son. II, II) empiezan las peregrinaciones del héroe para encontrar a un patrocinador. Colombo habla claramente de una scoperta, de un descubrimiento. Dice al rey de Portugal (que es error burlesco por España):

[...] --Io avrebbe l'intenzione,

si lei m'ajuta, de scoprí l'America-

[...] Yo tendría la intención,

si usted me ayuda, de descubrir América.

Pero aquí empiezan los problemas, pues además de las dudas:

Ma st'America c'è? ne siete certo?

¿Pero esta América la hay? ¿Está usted seguro?

Hay que hacer cuentas con la burocracia (son. IV-IX):

E li ministri de qualunque Stato

so' stati sempre tutti de 'na setta.

Irre orre, te porteno in barchetta,

e te fanno contento e cojonato.

$Y$ los ministros de cualquier Estado

han sido siempre todos de una secta.

Bla bla bla, te dan las diez mil vueltas

$y$ te dejan contento y bien burlado.

El soneto IX es una tirada contra los eternos curas que, solapadamente, se oponen a cualquier adelanto:

Che mettetelo in testa, che er pretaccio è stato sempre lui, sempre lo stesso.

Er prete? è stato sempre quell'omaccio nimico de la patria e del progresso.

Pues ponte en la cabeza que don cura ha sido siempre igual, y es siempre el mismo. ¿El cura? siempre ha sido aquel mal hombre enemigo de la patria y del progreso.

Finalmente, intercede la reina (son. X-XII) y da inicio el viaje (son. XIIIXVII). Un largo espacio está dedicado a los intentos de motín de la tripulación 
y a la hábil y apasionada maniobra de Colombo para apaciguarlos (son. XVIIXXII), y se llega finalmente al momento de la emoción:

Terra... Terra!... Peccristo!... E tutti quanti rideveno, piagneveno, zompaveno...

Terra... Terra!... Peccristo!... Avanti... Avanti!

Tierra... ;Tierra!... Por Cristo... Y todos juntos

se reian, lloraban y brincaban...

Tierra... iTierra!... Por Cristo... ;Ea! ;Adelante!

El soneto XXIV presenta una interrupción por parte de los escuchas, que se burlan del entusiasmo del narrador. Sigue la narración con las últimas dudas de la tripulación (son. XXv):

È l'Ámerica, sí, non c'è quistione; ma poi, si invece fosse un altro sito?

[...]

Vôr di' che poi, si voi nun ce credete, domani presto, ar primo che incontrate annàtejelo a di', che sentirete.

Es América, si, no cabe duda; pero ¿y si luego fuera otro lugar?

$[\ldots]$

Quiere decir que si no se convencen, por la mañana, al primero que vean díganselo, y a ver qué les contesta.

Se abre un paréntesis con la descripción de las maravillas lujuriantes de la selva tropical (son. XXVI y XXVIII):

Capischi? le piantine de cicoria j'arrivaveno qui, sopra la testa.

¿Comprendes? las plantitas de achicoria asi de altas, más que su cabeza.

$Y$, finalmente, el encuentro con el habitante, definido, sin más ni más, "salvaje", en un soneto famosísimo (XXIX):

$-E$ quelli? - Quelli? Je successe questa:

che mentre, lí frammezzo al villutello 
cosí arto, p'entra' ne la foresta

rompeveno li rami cor coltello,

Veddero un fregno buffo co' la testa

dipinta come fosse un giocarello, vestito mezzo ignudo, co' 'na cresta tutta formata de penne d'uccello.

Se fermorno. Se fecero coraggio:

-Ah quell'omo!, je fecero, chi sête?-

-Eh, fece, chi ho da esse'? So' un servaggio.

- ¿Y ellos?- ¿Ellos? Le pasó una cosa:

que mientras que alli en medio de la hierba

alta hasta aqui, para entrar en la selva

rompian el ramazal con el machete.

vieron a un tio chistoso, con la cara

pintada como fuese un muñequito,

vestido medio en cueros, $y$ por copete

una cresta de plumas de perico.

Se pararon. Se armaron de coraje:

-Aquel hombre, dijeron, ¿tú quién eres?-

-Jé, dijo, ¿qué he de ser? Soy un salvaje.

Las plumas, la desnudez, la extrañeza chistosa; el tipo se reconoce "salvaje", pero al mismo tiempo se perfila la taimada astucia de los blancos, que piden hablar con el que "manda", con el rey. Empieza (son. XXX) la relación, con la pregunta fatídica al rey:

$[\ldots]$ lei siete o non siete americano?

[...] usted eres o no eres americano?

El ingenuo contesta que no sabe cómo se llaman los lugares que habita, provocando la ironía del narrador:

Ma vedi sí in che modo procedevano!

Te basta dí che lí c'ereno nati

ne l'America, e manco lo sapeveno. 
¡Ve tủ de qué manera procedian!

baste decir que alli habian nacido,

en América, y ini se lo sabian!

Esta ingenuidad da pie al aprovechamiento de los blancos (son. XXXI y XXXII), que empiezan a embaucar a los infelices salvajes con la famosa venta de espejos y cuentas de vidrio a cambio de ceste de oro, canastos de oro. He aquí que hace falta una digresión sobre la dichosa ausencia de conceptos monetarios, en otro soneto cuyo cierre es archifamoso (XXXIII):

Perchè er servaggio, lui, core mio bello, non ci ha quattrini; e manco je dispiace; ché li er commercio è come un girarello. Capisci sí com'è? Fatte capace:

Io so' un servaggio e me serve un cappello: io ci ho ' $\mathrm{n}$ abito e so che a te te piace: io te do questo, adesso damme quello, sbarattamo la roba e sêmo pace

E così per li generi più fini, e così per la roba signorile; ma loro nun ce l'anno li quatrini.

Invece noi che semo una famijia de 'na razza de gente più civile, ce l'avemo, e er Governo se li pijia.

Porque el salvaje, él, corazón mio, no tiene feria, y tampoco le duele; pues el comercio alli va como un trompo. ¿Comprendes lo que digo? Oye y aprende:

Yo soy salvaje y me falta un sombrero.

Yo tengo un traje y sé que a ti te gusta: yo te doy esto, ahora dame aquello.

Trocamos nuestras chivas, y en santa paz.

$Y$ asi para los géneros más finos, asi para las cosas de los ricos; pero lo que es dinero, no lo tienen.

Nosotros al contrario, que formamos la familia de razas más civiles. lo tenemos, y el Gobierno se lo lleva. 
El asunto de las cuentas de vidrio no carece de consecuencias, porque lo ingenuo no quita lo valiente: los salvajes son bondadosos, pero necesitan ser tratados con la misma bondad:

Che dichi? che nun ci hanno l'istruzione?

Ma intanto so' de core e so' reale;

e tu finchè lo tratti co' le bone, nun c'è caso che lui te facci male.

¿Qué dices? ¿Que no tienen instrucción?

Pero son gentes buenas y cabales;

$y$ mientras tú los tratas por las buenas

no hay riesgo alguno que te hagan mal.

Lo que significa que los mentados salvajes empiezan a responder con flechazos a los timos de los blancos (son. XXXV). Otro asunto espinoso se mezcla: las mujeres (son. XXV-XXVII). Como todo asunto amoroso, es cosa de dos: a las salvajitas no les disgusta para nada el asunto:

Perchè le donne, poi, quelle ce stavano.

Pues las mujeres, la verdad, le entraban.

Digresión racial: el blanco arrasa (fa furore), y si la morena, que Dios nos libre, lo saborea (si Dio liberi l'assaggia), no lo quiere soltar; ella, sin embargo, tiene un problemita que puede echar a perder el idilio:

puzza un po' dell'odore della bufola.

hiede un poco con olor a búfala.

Esto da pie a nuestro narrador para alabar las sanas costumbres matrimoniales de los salvajes, en comparación con las complicaciones de la civilización, con un soneto (XXXVIII) que se ha quedado proverbial:

Ma perchè? Perchè? lí nun c'è impostura:

chè lí, quando er servaggio è innamorato, che lui decide de cambià de stato, lo cambia co' la legge de natura.

Invece qui le carte, la scrittura, er municipio, er sindico, er curato... Er matrimonio l'hanno congegnato, che quanno lo vôi fa', mette pavura. 
E dove lassi poi l'antri pasticci

der notaro? La dote, er patrimonio...

Si invece nun ce fossero st'impicci,

che te credi che ce se penserebbe?

$\mathrm{Si}$ ar monno nun ce fosse er matrimonio,

ma sai si quanta gente sposerebbe!

¿Por qué? ¿por qué? porque alli no hay mentira:

alli, cuando el salvaje se enamora,

que se decide, y va a cambiar de estado,

lo cambia con la ley de la natura.

En cambio aqui, papeles, escrituras,

El registro civil, alcaldes, curas...

El matrimonio lo tienen arreglado,

que si lo quieres, mueres espantado.

¿Y qué me dices de los otros líos

del notario? la dote, el patrimonio...

Si no existieran todas estas trabas,

¿crees que alguien acaso dudaria?

Si en el mundo no existiera el matrimonio,

jvieras tú cuánta gente casaria!

La aventura de Colombo llega a su fin. Él y los suyos empaquetan cuanta mercancía espectacular puede caber en sus barcos (son. XXXIX) y llegan a la ingrata patria (son. XL). Después de la acogida llena de curiosidad y ovaciones empieza la sarabanda de las envidias y las traiciones (son. XLI). Tres sonetos se dedican a relatar y reflexionar sentenciosamente sobre la triste experiencia de Colombo de vuelta a España (XLII-XLV). El soneto XLVI presenta una interrupción por parte de uno de los compañeros de bebida del narrador, y sirve para introducir la fatídica pregunta:

ma dico, dimme un po', ma tu lo sai

si lui, Colombo, proprio de dov'era?

pues digo, dime, pero ¿tú de veras

te sabes si él, Colombo, de dónde era? 
Los últimos sonetos, partiendo de la afirmación triunfalista de la italianidad de Colombo, exaltan el genio itálico con toda la seriedad que se puede esconder bajo una expresión tan ingeniosa e irresistiblemente cómica:

E che òmini! Sopra ar naturale, che il mondo ce l'invidia e ce l'ammira.

E l'italiano ci ha quer naturale che el talentaccio suo se lo rigira.

Pe' n'ipotise; vede uno che tira su 'na lampena? Fa mente locale e te dice: sapé, la terra gira.

Ce ripensa, e te scopre er cannocchiale.

E quell'antro? te vede 'na ranocchia ch'era morta; la tocca co' ' $n$ zeppetto e s'accorge che move le ginocchia.

Che fa? Te ce congegna un meccanismo; a un antro nun $j$ 'avrebbe fatto effetto; l'italiano t'inventa er letricismo.

¿Y qué hombres! de verdad portentos por los que el mundo nos envidia y admira.

$Y$ el italiano tiene por natura

el arte de dar vuelta a su talento.

Pon el caso: ¿ve a alguien que está izando una lámpara al techo? reflexiona, $y$ te dice: ya está, la tierra gira.

Piensa otra vez, e inventa el telescopio.

¿Y aquel otro? Ve un renacuajo muerto; lo empieza a cosquillear con un palito $y$ ve que está moviendo las rodillas.

¿Qué hace? Le congenia un mecanismo. A otro, no le habría causado efecto; el italiano te inventa el "ectricismo".

Colombo hace parte de esta nación privilegiada, y descubrió América perchè era lui, porqué era él: 
Si invece fosse stato un forastiere, che ce scopriva! Li mortacci sui!

Si a cambio hubiese sido un forastero ¿qué descubria? ¡los huesos de su abuela!

$Y$ eso que no contaba con los apoyos ni con la tecnología debida:

Si ci aveva l'ordegni de marina che se troveno adesso ar giorno d'oggi, ma quello ne scopriva una ventina!

De tener los instrumentos de marina que se encuentran hoy día, aquél, de Américas, idescubría por lo menos una veintena!

La gracia y el salero no ocultan la realidad: la visión de la gran epopeya americana carece de penetración en la otredad, de la consideración del punto de vista ajeno. La perspectiva con que Pascarella considera al indígena no pasa de ser la del dieciochesco mito del "buen salvaje", envejecido desde hacía un buen siglo. Detrás de aquellos versos se asoma un Voltaire trasnochado (por ejemplo, cuando Pascarella relata la forma natural del matrimonio parafrasea muy de cerca un pasaje de $L$ 'Ingenu). La edificación de la Nueva Italia parece haber entorpecido aquella capacidad otrora tan nuestra, tan de los italianos probados por sus propias desventuras, de simpatizar con las tragedias históricas ajenas; y parece haber desensibilizado el italiano hacia todo otro problema que no sea la reafirmación de los valores nacionales.

Parini, contemporáneo de Voltaire pero con pensamiento ilustrado hondamente moral y humanitario, resulta tener una visión mucho más cercana a nuestra sensibilidad moderna, y nos sigue transmitiendo desde su lejana periferia literaria y filosófica una extraordinaria y atemporal lección de compasión histórica. ${ }^{2}$

${ }^{2}$ En las traducciones se ha tratado de respetar tres elementos: sentido, registro verbal y ritmo, dando mayor importancia al sentido. No se ha tratado de reproducir el sistema de rimas de Pascarella (que construye sus sonetos con el esquema clásico ABBA ABBA CDC $E D E)$. Ocasionalmente se han introducido asonancias y consonancias sin esquema.

La scoperta de l'America aparece en Cesare PASCARELlA, I sonetti. Storia Nostra. Le prose. Milán, Mondadori, 1955, pp. 89-140. La edición consultada de Il giorno es la que se menciona en la nota 1. 